\title{
Parental Depressive Feelings, Parental Support, and the Serotonin Transporter Gene as Predictors of Adolescent Depressive Feelings: A Latent Growth Curve Analysis
}

\author{
Eeske van Roekel - Rutger C. M. E. Engels • \\ Maaike Verhagen · Luc Goossens • Ron H. J. Scholte
}

Received: 22 January 2010/ Accepted: 12 June 2010/Published online: 3 July 2010

(C) The Author(s) 2010. This article is published with open access at Springerlink.com

\begin{abstract}
Parental support and parental depressive feelings are found to be associated with depressive feelings in adolescent boys and girls, but results are inconsistent. In addition, the 5-HTTLPR genotype has been found to interact with environmental stressors in predicting adolescents' depressive feelings, but this has not been examined longitudinally. Therefore, the present study examined the relationships between parental support, parental depressive feelings, and adolescent depressive feelings. In addition, the relationships between the 5-HTTLPR genotype and adolescent depressive feelings were explored, as well as gene-environment interactions. Adolescents $(N=306$; Girls $\left.=53.3 \% ; M_{\text {age } \mathrm{T} 1}=13.4\right)$ filled out questionnaires at five annual waves and provided saliva samples for DNA. Latent growth curve modelling (LGCM) was used to examine the baseline level and the change in depressive feelings over time. Maternal support was related to baseline levels of depressive feelings in girls, whereas paternal support was related to baseline levels in boys. Paternal depressive feelings were only related to boys' depressive feelings at baseline, and maternal depressive feelings were not related to any outcome measures. Furthermore, no associations were found between 5-HTTLPR genotype and adolescent depressive feelings, and no gene-environment
\end{abstract}

E. van Roekel $(\varangle)$ · R. C. M. E. Engels · M. Verhagen ·

R. H. J. Scholte

Behavioural Science Institute, Radboud University Nijmegen, P.O. Box 9104, 6500 HE Nijmegen, The Netherlands

e-mail: G.vanRoekel@bsi.ru.nl

L. Goossens

The Research Group School Psychology and Child and Adolescent Development, Catholic University Leuven, Leuven, Belgium interactions emerged. Limitations of the study and implications of the findings are discussed.

Keywords Adolescence - Depressive feelings · Parental support · Parental depressive feelings . Serotonin transporter gene

\section{Introduction}

Depression is a common problem worldwide (WHO 2010) and can have severe consequences such as poor psychosocial adjustment (Coryell et al. 1993), poor quality of life, and suicide (Kandel et al. 1991). Longitudinal studies have shown that depression prevalence rates increase in early adolescence (Cole et al. 2002) and decrease throughout middle and late adolescence (Needham 2008). As depression can have severe consequences, it is important to examine its antecedents. In adolescence, parental influences are important predictors of depressive feelings. Both parental support and parental depression are found to be related to depression in their offspring (for meta-analyses, see Kane and Garber 2004; McLeod et al. 2007). Next to these environmental influences, interest has shifted towards examining the genetic factors underlying depression. So far, molecular genetic studies on depression have almost solely focused on adult depression. Many studies have examined the influence of a common polymorphism in the promoter region of the serotonin transporter gene (5-HTTLPR) (Furlong et al. 1998; Lasky-Su et al. 2005; López-León et al. 2008; Lotrich and Pollock 2004). Because adolescence is an important period in the development of depression, the focus of the present study is on the role of both environmental (i.e., parental support and parental depression) and genetic factors (i.e., the serotonin 
transporter gene) in the development of depressive feelings in adolescence. Additionally, because several studies have suggested gene by environment interactions in relation to depressive feelings (for review, see Uher and McGuffin 2008), we will also examine interactions between the 5-HTTLPR genotype and parental support and parental depressive feelings.

\section{Familial-Environmental Factors}

Parenting behaviors are important in depressive feelings in childhood (for meta-analysis, see McLeod et al. 2007). More specifically, parental support is related to depressive symptoms and major depressive disorder (for review, see Alloy et al. 2006). In adolescence, sex differences exist, with girls reporting little maternal and paternal support showing higher levels of depressive symptoms than boys (e.g., Needham 2008). No same-sex or cross-sex effects between parental sex and adolescents' sex have been found, that is, both paternal and maternal support were related to depressive symptoms in boys and girls (Needham 2008). In addition to parenting, maternal depression (Goodman 2007) and, increasingly, paternal depression (Connell and Goodman 2002; Kane and Garber 2004) have come to be recognized as important correlates of adolescent depressive symptoms. Studies examining sex differences in these relationships report inconsistent results. Some studies found that girls are more affected by their mothers' depressive feelings than boys (Cortes et al. 2006; Sheeber et al. 2002), whereas other studies did not find any sex difference (Garber and Martin 2002; Windle and Dumenci 1998). For paternal depression, Kane and Garber (2004) reported in their meta-analysis that there are no sex differences in the relationship between paternal and adolescent depressive feelings: Both boys and girls showed higher levels of depressive feelings when their father was depressed. Because of these inconsistent results, the focus of the present study is on examining the relationships among parental support, parental depressive feelings, and adolescent depressive feelings, for boys and girls separately.

\section{Genetic Effects}

An alternative interpretation of the association between parental and adolescent depression is genetic inheritance of depressive "traits" across successive generations. As indicated earlier, a significant genetic component in depression has been found in behavioral genetic studies on child and adolescent depression. Shared environmental effects, which include parenting effects, also have a significant contribution to depression in childhood and adolescence (Burt 2009). Both type of effects, that is, genetic inheritance and parenting, may be at work in non-additive fashion, particularly when gene by environment interactions $(\mathrm{G} \times \mathrm{E})$ are found to operate. These interactions entail that specific genetic predispositions are much more likely to lead to adolescent depressive feelings when parents use a particular set of parenting techniques.

One of the candidate genes involved in such an interaction is a common polymorphism in the promoter region of the serotonin transporter gene (5-HTTLPR) (Furlong et al. 1998; Lasky-Su et al. 2005; López-León et al. 2008; Lotrich and Pollock 2004). The 5-HTTLPR genotype is a variable repeat sequence in the promoter region of the gene, which encodes two allelic variants: a short allele (14 copies of the repeat unit) and a long allele (16 copies). Short allele carriers have been found to display stronger amygdala activation in response to threatening stimuli (Munafò et al. 2008), indicating problems with emotion regulation in short allele carriers. Interestingly, these problems with emotion regulation in short allele carriers are also found in healthy individuals, which implies that carrying the short allele may be a susceptibility factor that can lead to serious mental problems in the presence of negative environmental conditions (i.e., the 'double hit' hypothesis; Murphy et al. 2008). This presumed mechanism might explain why the 5-HTTLPR genotype is often found to be related to depression, either directly or in gene $\times$ environment interactions.

Meta-analyses examining the direct associations between the 5-HTTLPR genotype and depression in adults have reported inconsistent results. Three meta-analyses found significant, though small, associations between the short allele and depression (Furlong et al. 1998; LópezLeón et al. 2008; Lotrich and Pollock 2004), whereas another meta-analysis did not find significant associations (Lasky-Su et al. 2005). A possible explanation for these inconsistent results may be the differences in sample composition, sample size, and measurement of depression (Furlong et al. 1998; Lasky-Su et al. 2005). Because genes are known to interact with environmental factors in predicting behavior (Rutter 2007), gene by environment interactions have been examined as well. The results of the 5-HTTLPR polymorphism in $\mathrm{G} \times \mathrm{E}$ studies are inconsistent. Uher and McGuffin (2008) stated in their review that many studies indeed found support for gene $x$ environment interactions involving that particular gene, whereas Munafò et al. (2009) and Risch et al. (2009) concluded from their meta-analyses that these effects do not exist systematically.

Although adolescence may seem an important period in the development of depressive feelings, to our knowledge only three genetic studies have focused on this period (Åslund et al. 2009; Eley et al. 2004; Sjöberg et al. 2006). Eley et al. (2004) and Åslund et al. (2009) both found an increased risk for depression in female short allele carriers, whereas Sjöberg et al. (2006) found no such effects for 
either sex. All three studies also tested for gene $\times$ environment interactions. They found that 5-HTTLPR significantly interacted with adverse life events (Eley et al. 2004), with maltreatment (Åslund et al. 2009) or with conflicts in the family and psychosocial risks (Sjöberg et al. 2006), all in girls only. In these studies, female short allele carriers were at greater risk for depression in stressful environments. Up to now, only one study has examined the moderating role of the 5-HTTLPR genotype in the relation between perceived support from primary caregivers (mostly mothers) and depression in maltreated children (Kaufman et al. 2004). This study found that short allele carriers showed higher levels of depressive feelings when they experienced low levels of parental support. Therefore, we expect parental support to interact with the 5-HTTLPR genotype in predicting depressive symptoms. To our knowledge, this study is the first to examine the interaction between parental depressive feelings and the 5-HTTLPR genotype. We expect adolescents who both have parents with high levels of depressive feelings and carry a short allele to have the highest levels of depressive feelings.

\section{The Present Study}

The aim of the present study was to examine the relationships between parental support, parental depressive feelings, the 5-HTTLPR genotype, and the baseline level and development of depressive feelings in adolescence. The innovative aspects of the present study are (a) that we examine the development of depressive feelings over time using a longitudinal five-wave design, and (b) that we investigate the role of parental support, parental depression, and the 5-HTTLPR genotype in this development. We hypothesized low levels of parental support, high levels of parental depression, and the short allele of the 5-HTTLPR genotype to be directly related to higher initial levels and slower decrease in depressive feelings over time. Furthermore, we expected the 5-HTTLPR genotype to interact with parental support and parental depressive feelings in predicting adolescents' depressive feelings. Because results from previous studies showed that the effects of parental support, parental depression, and the 5-HTTLPR genotype may differ for boys and girls, we conducted the analyses for boys and girls separately.

\section{Method}

Procedure

For the present study, data from the "Family and Health" project were used, in which different socialization processes in relation to various health behaviors are examined in adolescents and their families (van der Vorst et al. 2005). Addresses of families with at least two children aged 13-16 years were derived from registers of 22 municipalities and invitation letters were sent. Families that agreed to participate were contacted by telephone to establish whether they fulfilled the following criteria: parents were married or living together, all family members were biologically related to each other, and the participating siblings were neither twins nor mentally of physically disabled. A further selection was made to obtain an equal distribution of sex constellations (boy-boy, girl-girl, boy-girl) and an equal division of adolescents' educational levels.

Data were collected in five annual waves. Trained interviewers visited the participants at home, asking all four family members to complete an extensive questionnaire individually, in his or her presence. The family members were not allowed to discuss the questions with each other. When all four family members completed the questionnaire, they received $€ 30$ (about \$43). Additionally, after completion of three waves, five travel cheques of $€ 1,000$ (about $\$ 1,422$ ) were raffled among the participating families. At T4, DNA samples were collected by means of saliva. A total of 311 unrelated adolescents agreed to be genotyped, five of these adolescents could not be genotyped. Data collection procedures were approved by the independent medical ethics committee METiGG in Utrecht, The Netherlands in 2006 (no. 6209).

\section{Participants}

The final sample comprised 428 Dutch families at the first wave (T1). Only data of the youngest adolescent in each family was used, because they were entering adolescence at T1, allowing us to examine changes in depressive feelings throughout adolescence. At the first wave, the mean age of these adolescents was 13.4 years $(S D=.50)$ and $53.3 \%$ of them were girls. One-third of the adolescents attended lower education (i.e., preparatory secondary school for technical and vocational training), one-third intermediate general education (i.e., preparatory secondary school for college), and one-third attended the highest level of secondary school (i.e., preparatory secondary school for university). Numbers of drop-outs were low, with 416 families $(97 \%)$ participating in the second wave (T2), 403 families (94\%) participating in the third wave (T3), 356 families (83\%) participating in the fourth wave (T4), and 313 families $(73 \%)$ at the fifth wave (T5).

Attrition analyses were conducted to examine whether adolescents who gave their consent for genotyping (participants; $n=306$ ) differed from the adolescents who did not (drop-outs; $n=122$ ). $T$-tests showed no significant differences between participants and drop-outs $(p>.05)$ in 
adolescents' depressive feelings, parental depressive feelings, maternal support, or age. Participants did experience a slightly lower level of paternal support than drop-outs $(t[425]=2.15, p=.033)$. For educational level and sex, Chi squares were calculated to examine differences between drop-outs and participants. For educational level, significant differences existed, indicating that participating adolescents had a higher level of education than those not included in the study $\left(\chi^{2}[416]=9.55, p=.008\right)$. No sex differences were found $\left(\chi^{2}[428]=0.37, p=.54\right)$.

\section{Measures}

\section{Adolescents' Depressive Feelings}

Depressive feelings were measured with a six-item questionnaire (Kandel and Davies 1982), translated into Dutch (Dékovic 1996). This questionnaire is often used in studies on adolescents (for a review, see Compas et al. 1993). Participants were asked how much they had been bothered by the following feelings in the past 12 months: feeling too tired to do things; feeling unhappy, sad, and depressed; having trouble going to sleep or staying asleep; feeling hopeless about the future; feeling nervous and tensed; and worrying too much about things. They could answer on a 5-point Likert scale, with answer categories varying from never (1) to always (5). Depressive feelings were assessed at all five time points. Cronbach's alpha varied between .78 and .85 , with a mean of .82 . Because this is a relative short questionnaire in comparison to other questionnaires such as the Beck Depression Inventory (BDI; Beck et al. 1961), Self-rating Depression Scale (SDS; Zung 1965) and Center for Epidemiological Studies Depression Scale (CES-D; Radloff 1977), we conducted a study among second-year psychology university students to examine the concurrent validity of this scale. This sample consisted of 202 Dutch students with a mean age of 22.50 years $(S D=4.03), 96 \%$ was female. The BDI consisted of 21 questions, alpha was .71. The SDS consisted of 20 items, alpha was .77. The CES-D consisted of 20 items, alpha for this scale was .84 . Results showed that the Kandel and Davies assessment highly correlated with the BDI $(r(200)=.61, p<.001)$, the SDS $(r \quad(196)=.73, p<.001)$, and the CES-D $(r(195)=.76, p<.001)$. This shows that the concurrent validity of the Kandel and Davies scale is good.

\section{Parental Depressive Feelings}

Both fathers and mothers filled out the same 6-item version of the Kandel and Davies questionnaire at baseline (T1) only, consisting of the same questions. We computed the mean scores for both maternal and paternal depressive feelings separately, which represent the average levels of depressive feelings at baseline.

\section{Perceived Parental Support}

To assess perceived parental support, we used a 12-item version of the Relational Support Inventory (RSI; Scholte et al. 2001), tapping several aspects of emotional support (e.g., 'This person shows me that he/she loves me') and instrumental support (e.g., 'This person explains or shows how I can make or do something'). Participants completed this questionnaire for their father and their mother separately at $\mathrm{T} 1$. Each item was scored on a 5-point Likert scale ranging from very untrue (1) to very true (5) and scores were averaged across items for each parent separately. Therefore, total scores ranged between 1 and 5. Alpha was .77 for maternal support and .80 for paternal support.

\section{5-HTTLPR Genotyping}

Genotyping of the HTTLPR polymorphism in the SLC6A4 (5-HTT, SERT) gene was performed by simple sequence length analysis. PCR was on $50 \mathrm{ng}$ genomic DNA using $10 \mathrm{pmol}$ of forward primer (5'-GCGTTGCCGCTCTGA ATGC- $3^{\prime}$ ) and 10 pmol reverse primer (5'-GAGGGACT GAGCTGGACAACCAC- $3^{\prime}$ ), $0.25 \mathrm{mM}$ dNTPs, $0.5 \mathrm{U}$ Taq DNA polymerase (Invitrogen, Breda, The Netherlands) in a PCR buffer containing $0.3 \mathrm{M}$ Tris- $\mathrm{HCl}(\mathrm{pH} 8.5), 75 \mathrm{mM}$ ammoniumsulfate and $7.5 \mathrm{mM} \mathrm{MgCl}{ }_{2}$. The cycling conditions for the polymerase chain reaction started with $5 \mathrm{~min}$ at $92^{\circ} \mathrm{C}$, followed by 35 cycles of $1 \mathrm{~min}$ at $92^{\circ} \mathrm{C}$, $1 \mathrm{~min}$ at the optimized annealing temperature $\left(57.5^{\circ} \mathrm{C}\right)$, and $1 \mathrm{~min} 72^{\circ} \mathrm{C}$, then followed by an extra $5 \min 72^{\circ} \mathrm{C}$. PCR products were analyzed on a $2 \%$ agarose gel. The amplification yielded distinct bands at 484 bp (short "s" allele) and $528 \mathrm{bp}$ (long "l" allele). To investigate the random genotyping error rate, the lab included 5 duplicate DNA samples per 96-well plate, which were $100 \%$ consistent. In addition, 4 blancs were included in each plate, which were required to be negative. By running PEDCHECK (O'Connell and Weeks 1998) for single point Mendelian inconsistencies on the markers, we identified one family with potential pedigree errors. This family was removed from the analysis. Hardy-Weinberg equilibrium (HWE) proportions were estimated from parental genotype information using the Markov-Chain Monte-Carlo approximation of the exact test implemented in the GENEPOP package V 3.3 (Raymond and Rousset 1995). No deviations from HWE were detected $(p=.96)$. Because the short allele is assumed to act dominantly (Heils et al. 1996; Hranilovic et al. 2004), the 5-HTTLPR genotype was dummy-coded into 1 (short-short and short-long) and 2 (long-long), to maximize the power of the analyses. 
Analyses

We used latent growth curve modeling (LGC) to examine the individual development of depressive feelings at baseline (i.e., intercept), and the change in depressive feelings over time (i.e., slope; Duncan et al. 2006). An advantage of this approach is that it is not assumed that all adolescents start at the same level of depressive feelings at baseline and progress in depressive feelings at the same rate: Individual growth is examined for each adolescent separately. Hence, LGC is an excellent way to take individual variations in the development of depressive feelings into account and to determine which variables are associated with these different changes over time. Mplus (Muthén and Muthén 1998-2007) was used for these analyses. Parameters in the models were estimated by applying the maximum likelihood estimator with robust standard errors (MLR). This estimator was developed to obtain robust standard errors when dependent variables have a non-normal distribution. To make optimal use of the data, we used the full-information maximum likelihood (FIML) approach. In this approach, all available information in the data will be used, using pairwise comparisons (Muthén and Muthén 1998-2007).

The model without the predictors was tested first. The mean of the intercept in this model represents the average level of depressive feelings at baseline. The mean of the slope provides information about the average rate of change in depressive feelings across the five annual waves. Second, we tested in four separate models whether maternal support, paternal support, maternal depressive feelings, and paternal depressive feelings were related to the baseline level and rate of change in adolescents' depressive feelings. This was done by regressing the intercept (baseline level) and slope (rate of change) of adolescents' depressive feelings on these parental variables. Subsequently, we tested the genetic effects on the intercept and slope in five separate models: (1) the direct effect of the 5-HTTLPR genotype, (2) the interaction between the 5-HTTLPR genotype and maternal support, (3) the interaction between the 5-HTTLPR genotype and paternal support, (4) the interaction between the 5-HTTLPR genotype and maternal depressive feelings, and (5) the interaction between the 5-HTTLPR genotype and paternal depressive feelings. Because one of our aims was to examine sex differences, all models were tested by multigroup analyses across sex (i.e., we analyzed the statistical associations among the variables separately for boys and girls). The results reported are thus all split by sex, as we did not analyze the results for the total group given our focus on examining sex differences. All variables were centered before computing the interaction terms, to avoid multicollinearity. Model fit was assessed by the following global fit indices: $\chi^{2}$, CFI (with a cut-off value of .90 for acceptable fit) and RMSEA (with a cut-off value of .10) (Hu and Bentler 1999).

\section{Results}

\section{Descriptive Statistics}

Of the 306 participants, 55 (18\%) were homozygous for the short allele, 147 (48\%) carried the heterozygous genotype, and 104 (34\%) were homozygous for the long allele.

Means, standard deviations, and Pearson correlations among model variables can be found in Table 1. Average levels of depressive feelings were low for adolescents and their mothers and fathers (i.e., between 2 and 2.5 on a 5-point scale), whereas both maternal and paternal support

Table 1 Correlations among model variables

\begin{tabular}{|c|c|c|c|c|c|c|c|c|c|c|c|c|c|}
\hline Variable & $M$ & $S D$ & 1 & 2 & 3 & 4 & 5 & 6 & 7 & 8 & 9 & 10 & 11 \\
\hline 1. 5-HTTLPR ${ }^{\mathrm{a}}$ & & & - & & & & & & & & & & \\
\hline 2. $\mathrm{Sex}^{\mathrm{b}}$ & & & -.03 & - & & & & & & & & & \\
\hline 3. Depressive feelings (T1) & 2.47 & .67 & .01 & $.17 * *$ & - & & & & & & & & \\
\hline 4. Depressive feelings (T2) & 2.56 & .73 & .04 & $.26 * *$ & $.56 * *$ & - & & & & & & & \\
\hline 5. Depressive feelings (T3) & 2.54 & .69 & -.03 & $.22 * *$ & $.50 * *$ & $.62 * *$ & - & & & & & & \\
\hline 6. Depressive feelings (T4) & 2.31 & .71 & .04 & $.19 * *$ & $.41 * *$ & $.50 * *$ & $.52 * *$ & - & & & & & \\
\hline 7. Depressive feelings (T5) & 2.28 & .69 & .08 & $.20 * *$ & $.42 * *$ & $.43 * *$ & $.49 * *$ & $.60 * *$ & - & & & & \\
\hline 8. Depressive feelings (mother) & 2.43 & .57 & .05 & .06 & .10 & .04 & .11 & $.15^{*}$ & $.12^{*}$ & - & & & \\
\hline 9. Depressive feelings (father) & 2.23 & .59 & .01 & .09 & .10 & .11 & .11 & $.20 * *$ & $.19 * *$ & $.12 *$ & - & & \\
\hline 10. Support (mother) & 4.11 & .41 & .01 & .09 & $-.20 * *$ & $-.12 *$ & $-.17 *$ & -.01 & .02 & -.09 & -.06 & - & \\
\hline 11. Support (father) & 3.92 & .47 & -.05 & .11 & $-.15^{* *}$ & -.06 & $-.14 * *$ & -.04 & -.08 & -.09 & -.05 & $.61 * *$ & - \\
\hline
\end{tabular}

5 -HTTLPR $=$ Serotonin transporter gene. ${ }^{\mathrm{a}} 1=$ short-short, short-long; $2=$ long-long. ${ }^{\mathrm{b}} 1=$ boy; 2 = girl

$* p<.05$. ** $p<.01$ 
was high (i.e., around 4 on the same 5-point scale). The level of adolescent depressive feelings decreased significantly over time (Wilks' $\Lambda=.83, F[4,255]=12.88$, $p<.001)$. Maternal and paternal depressive feelings were significantly related. Both paternal and maternal depressive feelings were positively related to adolescent depressive feelings at T4 and T5. Parental support was not related to parental depressive feelings. Furthermore, the 5-HTTLPR genotype was not related to any of the model variables.

\section{Model Findings}

The model without predictors was tested first. The intercept and slope of depressive feelings were significant $\left(\beta_{0}=\right.$ $2.55, p=.00 ; \beta_{1}=-.06, p=.00$ ), showing that participants on average scored 2.55 on depressive feelings at baseline, and depressive feelings in general slowly decreased over time $\left(\chi^{2}[d f=10, n=306]=481.13\right.$, $\mathrm{CFI}=.90$, and RMSEA $=.12$ ). This model was also tested in a multi-group analysis, in which the results are stratified by sex. The baseline level of depressive feelings was 2.40 for boys and 2.69 for girls. The rate of change was similar in boys and girls $\left(\beta_{1}=-.06, p=.00\right.$, for both groups).

\section{Parental Support and Parental Depressive Feelings}

Subsequently, the four separate models with maternal support, paternal support, maternal depressive feelings, and paternal depressive feelings were tested (Table 2), stratified by sex.

Maternal support was only related to the baseline level of depressive feelings in girls $(\beta=-.34, p=.00)$, indicating that in girls, high levels of maternal support were related to lower levels of depressive feelings at baseline $\left(\chi^{2}\right.$ $[d f=26, n=306]=69.11, \mathrm{CFI}=.89$, and RMSEA $=$ .11). For paternal support, a negative relation was found with baseline levels of depressive feelings for both boys $(\beta=-.39, p=.00)$ and girls $(\beta=-.26, p=.04)\left(\chi^{2}\right.$ $[d f=26, n=306]=60.29, \mathrm{CFI}=.91$, and RMSEA $=$ .10 ), indicating that high levels of support were related to low levels of depressive feelings at baseline. No relationships were found with the rate of change in depressive feelings. As can be seen in Table 2, maternal depressive feelings were neither related to the baseline level nor to the rate of change in adolescent depressive feelings $\left(\chi^{2}\right.$ $[d f=26, n=306]=57.67, \mathrm{CFI}=.91$, and RMSEA $=$ .10). However, paternal depressive feelings were related to the baseline level of depressive feelings in boys $(\beta=.44$, $p=.00$ ). Hence, high levels of paternal depressive feelings were related to high levels of depressive feelings at baseline, in boys only $\left(\chi^{2}[d f=26, n=306]=68.44\right.$, CFI $=$ .91 , and RMSEA $=.10)$.

\section{Genetic Factors}

In addition, we tested the effects of the 5-HTTLPR genotype and the gene-environment interactions (i.e., 5-HTTLPR $\times$ parental support and 5-HTTLPR $\times$ parental depressive feelings) in five separate models, for boys and girls separately (Table 3 ).

First, we examined the direct effect of the 5-HTTLPR genotype on the intercept and slope of depressive feelings $\left(\chi^{2} \quad[d f=26, \quad n=306]=73.62, \quad\right.$ CFI $=.90, \quad$ and RMSEA $=.11)$. The 5 -HTTLPR genotype was neither related to the intercept ( $\beta=.07, p=.44$ for boys, $\beta=$ $-.04, p=.70$ for girls) nor to the slope of adolescent depressive feelings $(\beta=.15, p=.24$ for boys, $\beta=.02$, $p=.87$ for girls). Additionally, we tested the associations between the gene-environment interactions and depressive feelings. As can be seen in Table 3, none of the geneenvironment interactions were significant. However, by conducting these multi-group analyses, we reduced the power of our analyses. Therefore, we also examined whether our results changed when we did not split the analyses by sex. This was not the case.

\section{Discussion}

Adolescence is an important developmental period in which prevalence rates of depression increase (Cole et al.

Table 2 Regression of initial level (intercept) and rate of change (slope) in adolescent depressive feelings on parental support and parental depressive feelings

\begin{tabular}{|c|c|c|c|c|}
\hline \multirow[t]{2}{*}{ Predictor } & \multicolumn{2}{|l|}{ Boys } & \multicolumn{2}{|l|}{ Girls } \\
\hline & Intercept & Slope & Intercept & Slope \\
\hline 1. Maternal support & $-.19(.12)$ & $.15(.20)$ & $-.34 * * *(.10)$ & $.22^{\dagger}(.15)$ \\
\hline 2. Paternal support & $-.39 * *(.11)$ & $.35^{\dagger}(.19)$ & $-.26 *(.13)$ & $.18(.14)$ \\
\hline 3. Maternal depressive feelings & $.15(.13)$ & $.04(.19)$ & $.11(.11)$ & $.16(.125)$ \\
\hline 4. Paternal depressive feelings & $.44 * * *(.09)$ & $-.13(.17)$ & $-.00(.11)$ & $.21(.14)$ \\
\hline
\end{tabular}

Note: Standard errors in parentheses. ${ }^{\dagger} p<.10 . * p<.05 . * * p<.01 . * * * p<.001$ 
Table 3 Regression of initial level (intercept) and rate of change (slope) in adolescents' depressive feelings on gene $\times$ environment interactions

\begin{tabular}{|c|c|c|c|c|}
\hline \multirow[t]{2}{*}{ Predictor } & \multicolumn{2}{|l|}{ Boys } & \multicolumn{2}{|l|}{ Girls } \\
\hline & Intercept & Slope & Intercept & Slope \\
\hline 1. 5-HTTLPR genotype & $.07(.09)$ & $.15(.13)$ & $-.04(.09)$ & $.02(.13)$ \\
\hline 2. 5-HTTLPR & $.05(.09)$ & $.13(.13)$ & $-.01(.10)$ & $-.00(.13)$ \\
\hline Maternal support & $-.14(.30)$ & $.83(.44)$ & $-.25(.32)$ & $-.13(.44)$ \\
\hline $5-H T T L P R \times$ maternal support & $-.03(.26)$ & $-.67(.40)$ & $-.05(.33)$ & $.30(.42)$ \\
\hline 3. 5-HTTLPR & $.04(.09)$ & $.11(.12)$ & $-.04(.09)$ & $.03(.13)$ \\
\hline Paternal support & $-.17(.29)$ & $.99(.45)$ & $-.27(.33)$ & $.19(.42)$ \\
\hline 5-HTTLPR $\times$ paternal support & $-.11(.25)$ & $-.71(.39)$ & $.04(.32)$ & $-.05(.41)$ \\
\hline 4. 5-HTTLPR & $.07(.09)$ & $.14(.13)$ & $-.04(.09)$ & $.02(.13)$ \\
\hline Maternal depressive feelings & $.12(.33)$ & $-.56(.40)$ & $-.02(.31)$ & $.46(.36)$ \\
\hline 5-HTTLPR $\times$ maternal depressive feelings & $-.09(.28)$ & $.69(.39)$ & $.13(.30)$ & $-.36(.37)$ \\
\hline 5. 5-HTTLPR & $.05(.09)$ & $.15(.13)$ & $-.04(.09)$ & $.03(.12)$ \\
\hline Paternal depressive feelings & $-.02(.34)$ & $.08(.42)$ & $.11(.31)$ & $-.27(.40)$ \\
\hline 5-HTTLPR $\times$ paternal depressive feelings & $.28(.28)$ & $-.04(.39)$ & $-.16(.31)$ & $.54(.42)$ \\
\hline
\end{tabular}

$5-H T T L P R=$ Serotonin transporter gene. $* p<.05 . * * p<.01 . * * * p<.001$

2002). Parents seem to play an important role in adolescents' depressive feelings (e.g., McLeod et al. 2007). Parenting behaviors, and more specifically, parental support, are important predictors of depressive feelings in adolescents (Alloy et al. 2006). Furthermore, maternal (Goodman 2007) and paternal depressive feelings (Connell and Goodman 2002; Kane and Garber 2004) are found to be related to adolescents' depressive feelings as well. In addition to environmental factors, genetic factors also play a role in the development of depressive feelings (e.g., Uher and McGuffin 2008). These findings served as the rationale for the present study that examined the relationships among parental support, parental depressive feelings, and the 5-HTTLPR genotype with the baseline level and development of depressive feelings over time in adolescents, using a longitudinal five-wave design. The present study is the first to examine relationships between the 5-HTTLPR genotype, gene by environment interactions and depressive feelings using a longitudinal design. Because previous studies examining sex differences within these relationships have found inconsistent results, the analyses were conducted for boys and girls separately. Sex differences were found in that girls' baseline levels of depressive feelings were related to parental support, but not to parental depressive feelings, whereas boys' depressive feelings at baseline were related to paternal support and paternal depressive feelings.

For girls, we found that both maternal and paternal support were negatively related to the baseline level of depressive feelings, whereas only paternal support was related to the baseline level in boys. This negative relation with the intercept (baseline level) is in line with our hypothesis and other studies on the role of parental support in depressive mood and feelings (e.g., Alloy et al. 2006;
Needham 2008; Sheeber et al. 2001). Our results indicate that both maternal and paternal support are important in girls' depressive feelings, whereas paternal support only plays a role in boys. A possible explanation for this pattern of findings may be that girls are more susceptible to the effects of low levels of parental support in general, which was also found by Needham (2008). A reason why only paternal support was related to depressive feelings in boys can be found in a modelling mechanism, in which boys model their same-sex parent more often than their crosssex parent (Bandura 1977). This same-sex association contradicts other studies examining the differential effects of maternal and paternal support, which found either no differential effects (Needham 2008), or even cross-gender effects (Stolz et al. 2005), in which boys were more affected by maternal support and girls were more affected by paternal support. Additional research on these associations is clearly needed.

We also found that paternal depressive feelings were strongly related to the baseline level of depressive feelings in boys, which is in line with an earlier study (Hops 1992). Similar to the effect of parental support, this same-sex effect can also be explained by a modelling mechanism, in which adolescents model their same-sex parent more often than their cross-sex parent (Bandura 1977). A possible explanation why we only found a relation between fathers' and boys' depressive feelings is that the influence of fathers on the development of their children is often found to be larger in older children, whereas the influence of mother is the largest in younger children (Connell and Goodman 2002). This may be because mothers are usually the primary caregivers in early childhood, whereas fathers become more actively involved when children grow older. 
We did not find an effect of the 5-HTTLPR genotype on the intercept or slope of depressive feelings. Additionally, the interactions of the 5-HTTLPR genotype with parental support and parental depression were not significant. This pattern of findings contradicts previous research using adolescent samples ( Sjöberg et al. 2006), in which direct gene effects and gene $\times$ environment interactions were found. However, recent meta-analyses have shown that the gene $\times$ environment interactions found in earlier studies are negligible (Munafò et al. 2009; Risch et al. 2009). Another explanation why we did not find any effect of the 5-HTTLPR genotype may be because depression is a polygenic, complex disorder, with great phenotypic heterogeneity. We were not able to differentiate between phenotypes of depression, such as major depression disorder with early age of onset, atypical depression, or severe depression. Future studies should differentiate between these phenotypes.

A number of limitations have to be mentioned that pertain to our sample and our measures of depressive feelings, environmental and genetic factors, respectively. First, our sample was relatively small and therefore possibly underpowered (Munafò et al. 2009). However, we did have a longitudinal design with measures at multiple time points, which increased the power of our analyses (Muthén and Curran 1997). Our sample was also composed of intact families only and different associations among maternal support, maternal depression and adolescent depressive feelings, for instance, may be found in other types of families such as single-parent families. Second, scores for depressive feelings were rather low in our sample and the adolescents and their parents did not have a clinical diagnosis of depression. Our measure examined depressive feelings and the 5-HTTLPR genotype may be associated with more severe types of depression only, such as major depression disorder with early age of onset or atypical depression. Still, most studies in which significant gene $x$ environment interactions were found also used questionnaires to assess depressive feelings or symptoms (Uher and McGuffin 2008). As mentioned before, the questionnaire used in the present study has good psychometric properties. Therefore, we do not expect that this method of phenotyping substantially influenced our findings. Third, our measure of environmental influences, that is, parental support and lack thereof, may have been too mild as a stressor in comparison to other studies examining gene by environment interactions in depression, which used strong stressors such as abuse or life events (Uher and McGuffin 2008). However, a previous study on depressive symptoms did find gene-environment interactions with parental support (Kaufman et al. 2004), and in a comparable study on loneliness, a significant gene-environment interaction between the 5-HTTLPR genotype and maternal support was found (Van Roekel et al. 2010). Therefore, we do think this was a suitable environmental stressor that can be used in gene by environment interactions. Fourth, the serotonin transporter gene may exert its effects in combination with other genes as depression probably is a polygenic disorder. However, because the present study used a relatively small sample, we were unable to test gene $\times$ gene interactions. For example, Cicchetti et al. (2007) found an interaction between 5-HTTLPR and the monoamine oxidase A gene (MAOA) in maltreated adolescents. Future studies with large samples should consider examining these gene $\times$ gene interactions.

In this study, we examined the role of parental support, parental depression, and the 5-HTTLPR genotype in adolescents' depressive feelings. Although we did not find an association between this genotype and depressive feelings, we have shown that parental support is linked to the baseline level of depressive feelings in adolescence. In order to avoid publication bias it is important that nonsignificant genetic effects are published (Uher and McGuffin 2008). Another pivotal finding of our study was that paternal depressive feelings affect the baseline level of boys' depressive feelings. This pattern of findings suggests that additional research on the impact of fathers in both aetiology and intervention research is clearly needed.

Open Access This article is distributed under the terms of the Creative Commons Attribution Noncommercial License which permits any noncommercial use, distribution, and reproduction in any medium, provided the original author(s) and source are credited.

\section{References}

Alloy, L. B., Abramson, L. Y., Smith, J. M., Gibb, B. E., \& Neeren, A. M. (2006). Role of parenting and maltreatment histories in unipolar and bipolar mood disorders: Mediation by cognitive vulnerability to depression. Clinical Child and Family Psychology Review, 9, 23-64.

Åslund, C., Leppert, J., Comasco, E., Nordquist, N., Oreland, L., \& Nilsson, K. W. (2009). Impact of the interaction between the 5HTTLPR polymorphism and maltreatment on adolescent depression: A population-based study. Behavior Genetics, 39, 524-531.

Bandura, A. (1977). Social learning theory. Englewood Cliffs, NJ: Prentice Hall.

Beck, A. T., Ward, C. H., Medelson, M., Mock, J., \& Erbaugh, J. (1961). An inventory for measuring depression. Archives of General Psychiatry, 4, 561-571.

Burt, S. A. (2009). Rethinking environmental contributions to child and adolescent psychopathology: A meta-analysis of shared environmental influences. Psychological Bulletin, 135, 608-637.

Cicchetti, D., Rogosch, F. A., \& Sturge-Apple, M. L. (2007). Interactions of child maltreatment and serotonin transporter and monoamine oxidase A polymorphisms: Depressive symptomatology among adolescents from low socioeconomic status backgrounds. Development and Psychopathology, 19, 11611180 . 
Cole, D. A., Tram, J. M., Martin, J. M., Hoffman, K. B., Ruiz, M. D., Jacquez, F. M., et al. (2002). Individual differences in the emergence of depressive symptoms in children and adolescents: A longitudinal investigation of parent and child reports. Journal of Abnormal Psychology, 111, 156-165.

Compas, B. E., Ey, S., \& Grant, K. E. (1993). Taxonomy, assessment, and diagnosis of depression during adolescence. Psychological Bulletin, 114, 323-344.

Connell, A. M., \& Goodman, S. H. (2002). The association between psychopathology in fathers versus mothers and children's internalizing and externalizing behavior problems: A metaanalysis. Psychological Bulletin, 128, 746-773.

Cortes, R. C., Fleming, C. B., Catalano, R. F., \& Brown, E. C. (2006). Gender differences in the association between maternal depressed mood and child depressive phenomena from Grade 3 through Grade 10. Journal of Youth and Adolescence, 35, 815826.

Coryell, W., Scheftner, W., Keller, M., Endicott, J., Maser, J., \& Klerman, G. L. (1993). The enduring psychosocial consequences of mania and depression. American Journal of Psychiatry, 150, $720-727$.

Dékovic, M. (1996). Vragenlijst Depressie bij Adolescenten (VDA) [Adolescent Depression Scale]. University of Utrecht, the Netherlands: Unpublished manuscript.

Duncan, T. E., Duncan, S. C., \& Strycker, L. A. (2006). An introduction to latent variable growth curve modeling: Concepts, issues, and applications (2nd ed. ed.). Mahwah, NJ: Erlbaum.

Eley, T. C., Sugden, K., Corsico, A., Gregory, A. M., Sham, P., McGuffin, P., et al. (2004). Gene-environment interaction analysis of serotonin system markers with adolescent depression. Molecular Psychiatry, 9, 908-915.

Furlong, R. A., Ho, L., Walsh, C., Rubinsztein, J. S., Jain, S., Paykel, E. S., et al. (1998). Analysis and meta-analysis of two serotonin transporter gene polymorphisms in bipolar and unipolar affective disorders. American Journal of Medical Genetics, 81, 467-474.

Garber, J., \& Martin, N. C. (2002). Negative cognitions in offspring of depressed parents: Mechanisms of risk. In S. H. Goodman \& I. H. Gotlib (Eds.), Children of depressed parents: Mechanisms of risk and implications for treatment (pp. 121-153). Washington, DC: American Psychological Associations.

Goodman, S. H. (2007). Depression in mothers. Annual Review of Clinical Psychology, 3, 107-135.

Heils, A., Teufel, A., Petri, S., Stober, G., Riederer, P., Bengel, D., et al. (1996). Allelic variation of human serotonin transporter gene expression. Journal of Neurochemistry, 66, 1-4.

Hops, H. (1992). Parental depression and child behavior problems: Implications for behavioural family intervention. Behaviour Change, 9, 126-138.

Hranilovic, D., Stefulj, J., Schwab, S., Borrmann-Hassenbach, M., Albus, M., Jernej, B., et al. (2004). Serotonin transporter promotor and intron 2 polymorphisms: Relationship between allelic variants and gene expression. Biological Psychiatry, 55, 1090-1094.

Hu, L., \& Bentler, P. M. (1999). Cutoff criteria for fit indices in covariance structure analysis: Conventional criteria versus new alternatives. Structural Equation Modeling, 6, 1-55.

Kandel, D., \& Davies, M. (1982). Epidemiology of adolescent depressive mood. Archives of General Psychiatry, 29, 12051212.

Kandel, D., Raveis, V. H., \& Davies, M. (1991). Suicidal ideation in adolescence: Depression, substance use, and other risk factors. Journal of Youth and Adolescence, 20, 289-309.

Kane, P., \& Garber, J. (2004). The relations among depression in fathers, children's psychopathology, and father-child conflict: A meta-analysis. Clinical Psychology Review, 24, 339-360.
Kaufman, J., Yang, B. Z., Douglas-Palumberi, H., Houshyar, S., Lipschitz, D., Krystal, J. H., et al. (2004). Social supports and serotonin transporter gene moderate depression in maltreated children. Proceedings of the National Academy of Sciences of the United States of America, 101, 17316-17321.

Lasky-Su, J. A., Faraone, S. V., Glatt, S. J., \& Tsuang, M. T. (2005). Meta-analysis of the association between two polymorphisms in the serotonin transporter gene and affective disorders. American Journal of Medical Genetics, 133, 110-115.

López-León, S., Janssens, A. C. J. W., González-Zuloeta Ladd, A. M., Del-Favero, J., Claes, S. J., Oostra, B. A., et al. (2008). Metaanalyses of genetic studies on major depressive disorder. Molecular Psychiatry, 13, 772-785.

Lotrich, F. E., \& Pollock, B. G. (2004). Meta-analysis of serotonin transporter polymorphisms and affective disorders. Psychiatric Genetics, 14, 121-129.

McLeod, B. D., Weisz, J. R., \& Wood, J. J. (2007). Examining the association between parenting and childhood depression: A meta-analysis. Clinical Psychology Review, 8, 986-1003.

Munafò, M. R., Brown, S. M., \& Hariri, A. R. (2008). Serotonin transporter (5-HTTLPR) genotype and amygdala activation: A meta-analysis. Biological Psychiatry, 63, 852-857.

Munafò, M. R., Durrant, C., Lewis, G., \& Flint, J. (2009). Gene $\times$ Environment interactions at the serotonin transporter locus. Biological Psychiatry, 65, 211-219.

Murphy, D. L., Fox, M. A., Timpano, K. A., Moya, P. R. Ren-Patterson, R., Andrews, A. M., et al. (2008). How the serotonin story is being rewritten by new gene-based discoveries principally related to SLC6A4, the serotonin transporter gene, which functions to influence all cellular serotonin systems. Neuropharmacology, 55, 932-960.

Muthén, B. O., \& Curran, P. J. (1997). General longitudinal modeling of individual differences in experimental designs: A latent variable framework for analysis and power estimation. Psychological Methods, 2, 371-402.

Muthén, L. K., \& Muthén, B. O. (1998-2007). Mplus User's Guide (5th ed.). Los Angeles, CA: Muthén \& Muthén.

Needham, B. L. (2008). Reciprocal relationships between symptoms of depression and parental support during the transition from adolescence to young adulthood. Journal of Youth and Adolescence, 37, 893-905.

O’Connell, J. R., \& Weeks, D. E. (1998). PedCheck: A program for identification of genotype incompatibilities in linkage analysis. American Journal of Human Genetics, 63, 259-266.

Radloff, L. S. (1977). The CES-D scale: A self-report depression scale for research in the general population. Applied Psychological Measurement, 1, 385-401.

Raymond, M., \& Rousset, F. (1995). GENEPOP (Version 1.2): Population genetics software for exact tests and ecumenicism. Journal of Heredity, 86, 248-249.

Risch, N., Herrell, R., Lehner, T., Liang, K., Eaves, L., Hoh, J., et al. (2009). Interaction between the serotonin transporter gene (5-HTTLPR), stressful life events, and risk of depression. Journal of the American Medical Association, 301, 24622471.

Rutter, M. (2007). Gene-environment interdependence. Developmental Science, 10, 12-18.

Scholte, R. H. J., van Lieshout, C. F. M., \& van Aken, M. A. G. (2001). Perceived relational support in adolescence: Dimensions, configurations, and adolescent adjustment. Journal of Research on Adolescence, 11, 71-94.

Sheeber, L., Davis, B., \& Hops, H. (2002). Gender-specific vulnerability to depression in children of depressed mothers. In S. H. Goodman \& I. H. Gotlib (Eds.), Children of depressed parents: Mechanisms of risk and implications for treatment (pp 253-274). Washington, DC: American Psychological Association. 
Sheeber, L., Hops, H., \& Davis, B. (2001). Family processes in adolescent depression. Clinical Child and Family Psychology Review, 4, 19-35.

Sjöberg, R. L., Nilsson, K. W., Nordquist, N., Öhrvick, J., Leppert, J., Lindström, L., et al. (2006). Development of depression: Sex and the interaction between environment and a promoter polymorphism of the serotonin transporter gene. International Journal of Neuropsychopharmacology, 9, 443-449.

Stolz, H. E., Barber, B. K., \& Olsen, J. A. (2005). Toward disentangling fathering and mothering: An assessment of relative importance. Journal of Marriage and Family, 67, 1076-1092.

Uher, R., \& McGuffin, P. (2008). The moderation by the serotonin transporter gene of environmental adversity in the aetiology of mental illness: Review and methodological analysis. Molecular Psychiatry, 13, 131-146.

Van der Vorst, H., Engels, R. C. M. E., Meeus, W., Deković, M., \& Van Leeuwe, J. (2005). The role of alcohol-specific socialization in adolescents' drinking behaviour. Addiction, 100, 1464-1476.

Van Roekel, E., Scholte, R. H. J., Verhagen, M., Goossens, L., \& Engels, R. C. M. E. (2010). Loneliness in adolescence: Gene $\times$ environment interactions involving the serotonin transporter gene. Journal of Child Psychology and Psychiatry, 51(7), 747-754.

Windle, M., \& Dumenci, L. (1998). An investigation of maternal and adolescent depressed mood using a latent trait-state model. Journal of Research on Adolescence, 8, 461-484.

World Health Organization (2010). Depression. Retrieved November 13, 2009, from http://www.who.int/mental_health/management/ depression/definition/en/index.html.

Zung, W. W. K. (1965). A self-rating depression scale. Archives of General Psychiatry, 12, 63-70.

\section{Author Biographies}

Eeske van Roekel is a $\mathrm{PhD}$ student at the Behavioural Science Institute of the Radboud University Nijmegen, the Netherlands. Her main research interests include adolescents' social-emotional development (especially loneliness and depression) and genetic influences.

Rutger C. M. E. Engels is a Professor at the Behavioural Science Institute of the Radboud University Nijmegen, the Netherlands. He received his $\mathrm{PhD}$ at Maastricht University. His main research interests concern adolescents' health risk behaviors.

Maaike Verhagen is an Assistant Professor at the Behavioural Science Institute of the Radboud University Nijmegen, the Netherlands. She received her PhD at the Radboud University Nijmegen Medical Centre. Her main research interests include genetic influences on internalizing behaviors in adolescents and adults.

Luc Goossens is a Professor at the Research Group School Psychology and Child and Adolescent Development of the Catholic University Leuven, Belgium. He received his $\mathrm{PhD}$ in developmental psychology from the Catholic University Leuven, Belgium. Current research interests include adolescent identity, autonomy, and loneliness.

Ron H. J. Scholte is an Associate Professor at the Behavioural Science Institute of the Radboud University Nijmegen, the Netherlands. His main research interest focuses on adolescents' and young adults' social development. 